\title{
NATIVE AND NON-NATIVE LISTENERS PERCEPTUAL JUDGEMENT OF ENGLISH ACCENTEDNESS, INTELLIGIBILITY, AND ACCEPTABILITY OF INDONESIAN SPEAKERS
}

\author{
Syifa' Khuriyatuz Zahro \\ English Education, Universitas Islam Darul Ulum Lamongan \\ Jl. Airlangga No. 03, Lamongan, Jawa Timur 62253, Indonesia \\ syifa'khuriyatuz@unisda.ac.id
}

Received: $12^{\text {th }}$ February 2019/Revised: $20^{\text {th }}$ February 2019/Accepted: $22^{\text {nd }}$ February 2019

How to Cite: Zahro, S. K. (2019). Native and non-native listeners perceptual judgement of English accentedness, intelligibility, and acceptability of Indonesian speakers. Lingua Cultura, 13(1), 39-44.

https://doi.org/10.21512/lc.v13i1.5362

\begin{abstract}
This research aimed at investigating the extent of accentedness and intelligibility as well as the acceptability of Indonesian foreign-accented speech perceived by native and non-native listeners, as well as finding their correlation to each other. It used qualitative research. The participant of the research was selected using purposive sampling. The participants were divided into speakers and listeners. There are six speakers and four listeners selected. The four listeners were native and nonnative listeners who rated and transcribed six recorded reading of Indonesian speakers by means of SPIN (Speech Perception in Noise) test. The results show that native listeners rate the speech almost the same way as non-native listeners do. The speeches with clear and accurate pronunciation are rated highly accepted and fully intelligible, regardless of having a very strong accent. In contrast, less clear and accurate pronunciations, as well as a very strong accent of the speeches, are rated unacceptable and still reasonably intelligible. The result of the correlation test between accentedness and intelligibility as well as accentedness and acceptability of the accent finds on no account of correlation to each other. Therefore, accentedness and intelligibility plus accentedness and acceptability of the accent are independent, so that strong foreign accent could stay acceptable and intelligible. The factors found to influence the judgment are the familiarity of the accent, clarity, and accuracy of pronunciation. Aforementioned findings have implication to challenge English teachers in Indonesia to develop meaningful activities to teach English pronunciation accurately to be regarded as fully intelligible and acceptable by listeners, especially native English listeners.
\end{abstract}

Keywords: native listeners, non-native listeners, perceptual judgement, English accentedness, English intelligibility, English acceptability

\section{INTRODUCTION}

It is a fact that numerous differences between the first language (L1) and the target language of the speakers has affected the way non-native speakers speak the target language. Non-native speakers definitely find it difficult to recognize the exact sounds of the target language in the correct pronunciation. In consequence, non-native speakers may produce the sound with some errors, mistakes as well as substitution influenced by their first language. One of the factors has influenced non-native speakers' speaking practice is an accent.

The influence of first language accent to speak a second or foreign language (FL) is a so-called foreign accent. Non-native speakers' pronunciation is affected by their native language accent, in which different from the pronunciation and phonological norm of the target language in speaking it (Behravan et al., 2016; Del Puerto, Lecumberri, \& Lacabex, 2015; Natalia, Andrew, \& George, 2017; Ryalls \& Perkins, 2017; Schroeder et al., 2016). Non-native speakers possibly produce a different degree of foreign accent compared to the expected pattern of target language pronunciation that is known as accentedness (Bergeron \& Trofimovich, 2017; Saito \& Shintani, 2016). Accentedness implicates the listeners' judgment of the extent to which a speaker is perceived as accented.

A foreign-accented speech requires non-native speakers' speech to be understood. Since speaking is believed and regarded as the success of language learning measurement (Leong \& Ahmadi, 2017), the intelligibility issue of foreign-accented speech experienced by the nonnative speakers is becoming apparent. For that reason, the 
intelligibility is the degree to which listeners are able to recognize and understand exact words, phrases, or sentences articulated by the speakers through the recording's sounds of the accented speakers. It is a complementary element of examination (Hopf, McLeod, \& McDonagh, 2017; Munro \& Derwing, 2015; Van Kuyk, Kleijn, \& Hendriks, 2018; Yazan, 2015).

Foreign-accented speech of speakers with different first language accent may result in different accentedness. The geographic distance undeniably affects the amount of effort to understand the foreign-accented speech of nonnative speakers. Indonesia has a distant separation to an English speaking country. Commonly, the Indonesian people communicate with their first language instead of Indonesian language as their second language (L2). Approximately, 366 ethnic groups in Indonesia are fluent in 669 languages and dialects (Suyanto, Setyowati, \& Pramono, 2017). Their L1 accent almost persists when they speak L2 or FL (Beinhoff, 2014) like speaking Indonesian, Arabic, and English. The foreign-accented speech also happens to an adult, including Indonesian people. It is argued that the phenomenon of foreign-accented English speech is caused by L1 background and failure production of target language sounds and intonation in the appropriate manner.

Some previous researches concerning accentedness and intelligibility have been sought by many linguist researchers. They have proposed that accentedness and intelligibility are autonomous that a strong accent of a foreign speech is an insignificant sign of the lower intelligibility (Hayes-Harb \& Hacking, 2015; Munro \& Derwing, 2015). Among previous research on accentedness of foreign-accented speech, there is a foremost issue about how the listeners perceive the acceptability of accented speech in relation to its accentedness. The investigation of the acceptability of foreign-accented speech in accordance with its accentedness as well as its intelligibility has been observed in Hong Kong and Japan. It is concluded that there is a moderate acceptance possibility of foreign accents in English speaking when there are no noticeable phonological features of L1 (Setter, Sewell, \& Ryder, 2014; Sugimoto \& Uchida, 2018).

It is essential for successful communication between speakers and interlocutors who have not shared the same language to make understandable utterances to prevent misunderstanding through being a proficient speaker and capable interlocutor to communicate in English as a lingua franca. Therefore, the result of current research is expected to be beneficial to provide a depiction of English native and non-native judgment toward foreign-accented speech experienced by many English speakers as foreign language including Indonesian. Besides that, it is also to know the level of intelligibility and acceptability of Indonesian foreign-accented speech to anticipate misinterpretation and confusion of weird sounds and strange pronunciation in order to succeed in English communication to English speakers around the world, specifically to those of native speakers.

In addition, it is expected to provide an insightful description of the judgment of Indonesian foreign-accented speech for English teachers and practitioner, especially Indonesian teachers. It can be a future concern and to invent teaching methods in teaching English pronunciation and speaking to Indonesian students who experienced a foreign accent in speaking the foreign language to make an intelligible and acceptable speech.

Based on the abovementioned background and to fulfill these expectations, this research investigates native and non-native listeners' perceptual judgment of English accentedness, intelligibility, and acceptability of Indonesian speakers. The research further examines the correlation between the judgment of accentedness and intelligibility analysis as well as the accentedness and acceptability of the accent judgment. The factors influenced how the judgment have been made is an additional researched issue.

\section{METHODS}

The current research is a qualitative research that aims to gain a pilot basis of native and non-native listeners' perception of foreign-accented English speech by Indonesian people. The case study includes the phenomenon of foreign accent in English speech by Indonesian people. The accents examined are based on the most peculiar regional accents in Indonesia perceived in a preliminary study. The peculiarity is believed as a result of some phonological absence and differences between English and the three accents. The regional accents are Banjarese, Sundanese, and Madurese. Due to a variety of accents investigated, a collective case study is applied to get a depth depiction of the multiple cases (Adams et al., 2014). Therefore, this research has a collective case characteristic in applied linguistics.

The participant of the research is selected by means of purposeful sampling. They are divided into speakers and listeners. There are six speakers and four listeners selected. The speakers are provided speech samples which sentences are taken from Speech Perception in Noise (SPIN) test. The selected sentence lists concern on some phonological aspect for each sentence. The participant's selection is made on the basis of some criteria to decide those who are able to provide a thoughtful data of the phenomenon being researched (Gentles et al., 2016; Palinkas et al., 2015).

The criteria of speakers' sampling are they have Indonesia nationality and particular regional language as mother tongue, they have experience in speaking English with L1 accent, attain 25 to 30 aged, and attend English educational background more than five years. To avoid gender bias, the balanced gender is selected for each of the subjects from a certain regional area.

Furthermore, the listeners are English native listeners (NL) and non-native listeners (NNL). Both NL and NNL are selected because more non-native speakers have spoken English than its native speaker. Consequently, there is a growing interaction between NNL and NNL. On account of the limitation to discover eligible native speakers from different nationalities, two American speakers are selected as NL. Meanwhile, the criteria of NNL are Indonesian people major in English and an EFL instructor or teacher for more than five years.

The verbal data in the form of the speech sample is collected by recording the speakers' speech through reading the 20 lists of SPIN sentences with the sum of 150 sentences adapted from Kalikow, Stevens, and Elliott (1977) and Bada (2001). The obtained recording is then given in the judgment task to rate or judge by the listeners relating to accentedness and acceptability of accented speech on six points Likert scale (Likert, 1932). To analyze the numeral data attained from the judgment, rating scales are applied for two elements; accentedness that is adapted from Allen (2006) and acceptability that is adapted from Palacios (2009).

Additionally, the intelligibility assessment is made 
by replicating previous researchers through a dictation task. NL and NNL are asked to transcribe in a standard orthography of a word by word listened from audiorecording (Jułkowska \& Cebrian, 2015; Munro \& Derwing, 2015). A comparison between the listeners' transcription and original SPIN sentences is formerly done to find out the amount of listeners' transcription correctness compared to the original to determine the level of intelligibility by six points Guttman scaling (Guttman, 1944). The analysis of the data of both accentedness and intelligibility as well as accentedness and acceptability of the accent is further examined through correlation test to picture whether there is a correlation between both of them.

All the obtained data is required to be established to create a sense and reduce partiality as well as confirm the conclusions (Amankwaa, 2016; Birt et al., 2016; Lather, 2017; Thomas, 2017). Therefore, a member is checked by interviewing the English native speakers (NS) who are required to provide feedback about the research's findings to get additional insight in avoiding something missed (Birt et al., 2016; Thomas, 2017). It is a technique attempted to gain the accurateness or reliability of the findings. As a final point, triangulation is applied to confirm the findings.

\section{RESULTS AND DISCUSSIONS}

The displayed figures in this section are the result of the judgment for accentedness, intelligibility, and acceptability of Banjarese, Sundanese, and Madurese accents. The coding method $(\mathrm{B}, \mathrm{S}$, and $\mathrm{M})$ is used as a representation of the speakers' accent (B stands for Banjarese, S stands for Sundanese, and M stands for Madurese). While NL and NNL are the listeners from native English and non-native English as what has been described in the research method section. Figure 1 shows the distribution of perceived accentedness judgement.

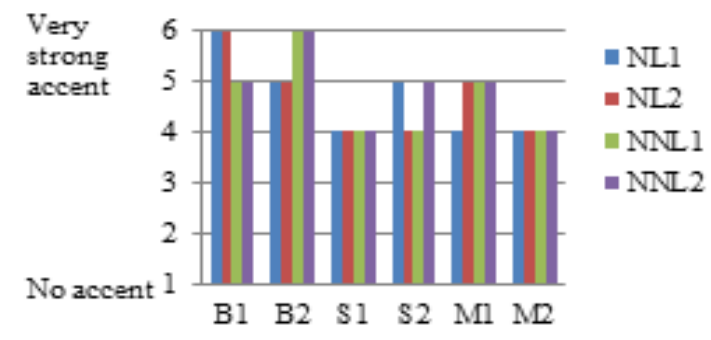

Figure 1 The Distribution of Perceived Accentedness Judgment

Figure 1 shows that most accented speakers are B1 and B2. Non-native listener rated B1 speaker is less accented than those of native listeners, while native listener rated B2 speaker is less accented than those of non-native listeners. The factors to affect the judgment are the clarity of the speech and the quality of the voice because some recordings have a poor quality of voice. The poorest pronunciation competency is considered to be the cause of the native listeners rating. They also consider that those very strong accented speakers must do less English speaking practice so that some strange sounds are found.

In addition, all the listeners agree to rate the S1 and M2 speaker as having slightly accented speech since they are familiar with the Sundanese and Madurese language.
Besides, some listeners perceive the S2 speaker as having a strong accent and the others perceive them as a slightly accented. One NL and two NNLs perceive the M1 speaker has a strong accent, but another NL rates it as slightly accented. In summary, the accentedness of Indonesian speakers is slightly accented, strong accented, and very strong accented in which are categorized as accented speech.

These results imply that different speakers may have a different level of foreign-accented speech even though they have identical local accented speech. First and foremost, all listeners agree that all the speeches are accented with different degree. Amongst the three accents under research, Banjarese accent is observed as having the highest level of foreign-accented speech of all. In accordance with the abovementioned result, the interview generated that Banjarese accent is also considered as the strangest accent compared to Sundanese and Madurese accent. Also, the interviewees suggest that there are two issues that influenced their judgment; clarity and accuracy of the speakers' pronunciation, and listeners' exposure to the local accent.

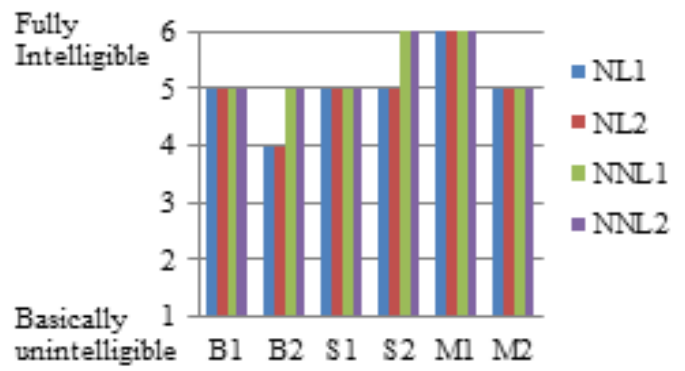

Figure 2 The Distribution of Perceived Intelligibility Level

Figure 2 demonstrates that there are three levels of perceived intelligibility of Indonesian speakers. The levels are in 4 (reasonably intelligible), 5 (largely intelligible), and 6 (fully intelligible) that indicate the intelligible speech. Impressionistically, among those six speakers, only M1 is regarded as having full intelligible speech. While B1, S1, S2, and M2 speakers are graded as having a largely intelligible speech, B2 speech is perceived as moderate intelligible to the listeners.

As a matter of fact, the high level of intelligibility of Indonesian speakers is not consistent with the result of accentedness judgment which suggests the high level of perceived accent. This entails that strong foreign accented speeches may be intelligible for the high amount of correctness in NL and NNL's transcription.

The interview in the result of member checking indicates that the NS is repeatedly contextualized the transcription of vague and strange pronunciation that is made by the speakers. They emphasize speakers' clarity of pronunciation much more affected how the transcription is made. Therefore, clarity of pronunciation is suggested as a must component to make the speech intelligible and understandable. This shows that some of the Indonesian speakers' pronunciation in English is still perceived as weird for NS. In brief, the result of intelligibility level of the foreign accent of Indonesian speakers is regarded in a positive way that the speech is intelligible (reasonably ineligible, largely intelligible, and fully intelligible). 
To relate the result of accentedness judgment and intelligibility level, the correlation test is conducted to both variables. It is found that the correlation coefficient ( $\mathrm{r}$ values) of both variables data is $-0,26$ which show a weak correlation where a strong accent is not always unintelligible. Thus, accentedness is not a sign of unintelligibility. This finding reinforces the earlier result by Munro and Derwing (2015) that there is a weak correlation between accentedness and intelligibility. They are rationally an independent element so that a strong accented speech possibly will be intelligible as well.

Furthermore, to further examine the correlation of accentedness and acceptability of the accent, it initially needs to describe the result of acceptability of the accent judgment. The result of the acceptability of the accent judgment is illustrated in Figure 3.

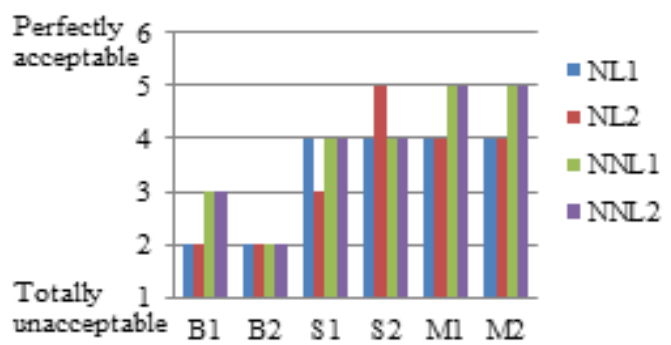

Figure 3 The Distribution of Perceived Acceptability of the Accent

Figure 3 demonstrates that the foreign accent of Indonesian speakers is at the level of 2 (unacceptable), 3 (slightly unacceptable), 4 (slightly acceptable), and 5 (acceptable). The M1 and M2 speakers are judged by NNL possessing an acceptable accent and rated by NL owning a slightly acceptable accent. Moreover, S2 speaker's accent is perceived as an acceptable accent by one NL but regarded as a slightly acceptable accent by other listeners in which is corresponding to the result of acceptability of S1 speaker's accent by three listeners. On the other hand, another NL regards S1 speaker's accent as a slightly unacceptable accent. Unfortunately, B1 and B2 speakers are mostly perceived having an unacceptable accent, except for NNL who rated B1 as having a slightly unacceptable accent. This shows that B1 speaker is perceived more positively by NNL rather than NL. Among the result of the acceptability judgment, B2 speaker gains the lowest result of the acceptability of the accent judgment by considering him as having an unacceptable accent by all the listeners.

Based on the result of the acceptability of the accent, it indicates that it is inconsistent with the result of accentedness. Speakers with a very strong accent are perceived both as unacceptable and acceptable. Meanwhile, speakers with a strong accent are regarded as either as a slightly acceptable or acceptable accent.

In addition, to reveal the correlation between accentedness and acceptability of the accent, a correlation test is also conducted. The result of the correlation test by SPSS 16.0 obtained the correlation coefficient (r-value) of both data is $-0,81$ that is indicated a significant negative correlation between accentedness and acceptability of the accent. It is found that accentedness and acceptability of the accent are independent where a very strong accent might be acceptable by both native and non-native listeners.
A further investigation is done by interview to examine the exploring factor that is affecting the judgment as discovered by previous researchers (Fuse, Navichkova, \& Alloggio, 2018; Huang, Alegre, \& Eisenberg, 2016; Kang, Thomson, \& Moran, 2019). The result yields that there are three factors affected on how a judgment is made; familiarity of the accent, clarity, and accuracy of pronunciation.

The first factor affecting the judgment is the familiarity of the accent. The native listeners have less or even no familiarity with a Banjarese accent but fully familiar with a Sundanese accent and Madurese accent since they expose more time to interact with Bandung and Surabaya people. Such unfamiliarity may possibly influence the Banjarese accent judgment, whereas the Sundanese and Madurese speech are familiar for the listeners.

As a result, the listeners' familiarity with the accents offered a contributing element to the judgment of both the accentedness and acceptability of the accent. This is consistent with Fuse, Navichkova, and Alloggio (2018), Huang, Alegre, and Eisenberg (2016), and Kang Thomson, and Moran (2019) who have suggested listeners' familiarity is one of the factors affecting the evaluation of non-native English speech. However, this finding is not synonymous with research by Stocker (2017) who has found there is no familiarity influence on the judgment of accent.

The clarity and accuracy of speakers' pronunciation are two other factors that influenced the judgment. This is as what has been believed by NL who considered some of the speeches are unclear and have an inaccurate pronunciation. Therefore, the clarity and accuracy of pronunciation influence more to the accentedness and acceptability to the accent judgment. If non-native English speakers pronounce the English word differently compared to the exact English pronunciation norm, they will possibly be unacceptable accent regardless of possessing a very strong accent. Reversely, if the non-native English speakers articulate the English word clearly and accurately, they would be regarded as an acceptable accent although they are perceived as having a strong accent. In brief, accentedness and acceptability of accent judgment are mostly made on the basis of two major factors; the speakers' clarity and accuracy of pronunciation.

The issue of clarity of pronunciation is similar to earlier research findings that the purpose of pronunciation clarity is for easiness of interpretation and hearing of the spoken text in a way that no different pronunciation articulated by speakers' in comparison to those of native English speaker version. It is one of the foremost factors that influenced the judgment making (Munro \& Derwing, 2015; Sugimoto \& Uchida, 2018). Whereas the influence of speakers' pronunciation accuracy in the judgment of accentedness and acceptability of the accent is a new factor found to affect the listeners' judgment of Indonesian speakers. To this effect, the accuracy of pronunciation should get significant attention for English teachers in Indonesia to give more emphasis on teaching accurate English pronunciation in English classes.

Summing up the analysis and discussion, it is found the influence of three factors on listeners' judgment of accentedness, intelligibility and acceptability of the accent toward Indonesian speakers are listeners' familiarity with the accent, speakers' clarity of pronunciation and their accuracy of pronunciation. The clarity of speakers' pronunciation more significantly gives an influence on how the judgment that is made by the listeners among those factors. 


\section{CONCLUSIONS}

The current research seeks to examine the issue of accentedness, intelligibility, and acceptability of the accent among Indonesian speakers ranging from Banjarese, Sundanese, and Madurese accent. The final summation is that the perception of both NL and NNL about the foreignaccented speech of Indonesian speakers mostly the same. The foreign-accented speech of Indonesian speakers is regarded as highly accented in level 6, (very strong accent), 5 (strong accent), and 4 (slightly accented), as well as mostly intelligible in the level 6 (fully intelligible), 5 (largely intelligible), and 4 (reasonably intelligible). Whereas, the level of acceptability of Indonesian foreign accented speech is perceived as either acceptable or unacceptable in the level of 2 (unacceptable), 3 (slightly unacceptable), 4 (slightly acceptable), and 5 (acceptable).

Moreover, the correlation value between accentedness and intelligibility is found $-0,26$ means a weak relationship, while the value of accentedness and acceptability of the accent is $-0,81$ which regarded as strong negative correlation. Therefore, accentedness and intelligibility, as well as accentedness and acceptability, are autonomous; in which strong accented speech is not always perceived as unintelligible and unacceptable speech. So that accentedness is a poor indication of intelligibility and acceptability of the accent. It reinforces the earlier research by Munro and Derwing (2015) who have asserted that no strong evidence of the correlation between accentedness and intelligibility. Thus, they are a separate component where a foreign-accented speech is possibly intelligible. Furthermore, these inconsistency findings and correlation test of both accentedness and acceptability indicate that accentedness and acceptability are as well independent to each other in which a strong accented speech may conceivably be acceptable.

Three factors are found to affect the way listeners both NL and NNL make the judgment of accentedness, intelligibility, and acceptability of the accent, they are: listeners' familiarity and exposure of the local accent, as well as speakers' pronunciation clarity as well as their accuracy. The familiarity of the accent factor is corroborated to some research (Fuse, Navichkova, \& Alloggio, 2018; Huang, Alegre, \& Eisenberg, 2016; Kang, Thomson, \& Moran, 2019). Clarity and accuracy of pronunciation is a novel factor that affected the judgment.

Based on that finding, it is suggested to the Indonesian English teachers to develop meaningful activities and provide authentic materials to teach English pronunciation accurately so that Indonesian speech is regarded as fully intelligible and acceptable by listeners, especially native English listeners. To future research, there is a need to consider phonetics or phonological analysis as a technique of data analysis which is expected to have a linguistics concern of the intelligibility of the speech.

\section{REFERENCES}

Adams, R., Jones, A., Lefmann, S., \& Sheppard, L. (2014). Utilising a collective case study system theory mixed methods approach: A rural health example. $B M C$ Medical Research Methodology, 14(1), 1-9. https:// doi.org/10.1186/1471-2288-14-94.
Allen, M. J. (2006). Assessing general education programs. San Francisco: Anker Publishing.

Amankwaa, L. (2016). Creating Protocols for Trustwortiness in Qualitative Research. Journal of Cultural Diversity, 23(3), 121-127.

Bada, E. (2001). Native language influence on the production of English sounds by Japanese learners. The Reading Matrix, 1(2), 1-15.

Behravan, H., Hautamäki, V., Siniscalchi, S. M., Kinnunen, T., \& Lee, C. H. (2016). I-Vector modeling of speech attributes for automatic foreign accent recognition. IEEE/ACM Transactions on Audio, Speech and Language Processing (TASLP), 24(1), 29-41.

Beinhoff, B. (2014). Perceiving intelligibility and accentedness in non-native speech: A look at proficiency levels. Concordia Working Papers in Applied Linguistics, 5, 58-72. https://doi. org/10.1080/026404101750070193.

Bergeron, A., \& Trofimovich, P. (2017). Linguistic dimensions of accentedness and comprehensibility: Exploring task and listener effects in second language French. Foreign Language Annals, 50(3), 547-566.

Birt, L., Scott, S., Cavers, D., Campbell, C., \& Walter, F. (2016). Member checking: A tool to enhance trustworthiness or merely a nod to validation? Qualitative Health Research, 26(13), 1802-1811.

Del Puerto, F. G., Lecumberri, M. L. G., \& Lacabex, E. G. (2015). The assessment of foreign accent and its communicative effects by naïve native judges vs. experienced non-native judges. International Journal of Applied Linguistics, 25(2), 202-224.

Fuse, A., Navichkova, Y., \& Alloggio, K. (2018). Perception of intelligibility and qualities of non-native accented speakers. Journal of Communication Disorders, 71, 37-51.

Gentles, S. J., Charles, C., Nicholas, D. B., Ploeg, J., \& McKibbon, K. A. (2016). Reviewing the research methods literature: Principles and strategies illustrated by a systematic overview of sampling in qualitative research. Systematic Reviews, 5(1), 172183.

Guttman, L. (1944). A basis for scaling qualitative data. American Sociological Review, 9(2), 139-150.

Hayes-Harb, R., \& Hacking, J. F. (2015). Beyond rating data: What do listeners believe underlies their accentedness judgments? Journal of Second Language Pronunciation, 1(1), 43-64. https://doi. org/10.1075/jslp.1.1.02hay.

Hopf, S. C., McLeod, S., \& McDonagh, S. H. (2017). Validation of the intelligibility in context scale for school students in Fiji. Clinical Linguistics \& Phonetics, 31(7-9), 487-502.

Huang, B., Alegre, A., \& Eisenberg, A. (2016). A crosslinguistic investigation of the effect of raters' accent familiarity on speaking assessment. Language Assessment Quarterly, 13(1), 25-41.

Jułkowska, I. A., \& Cebrian, J. (2015). Effects of listener factors and stimulus properties on the intelligibility, comprehensibility, and accentedness of L2 speech. Journal of Second Language Pronunciation, 1(2), 
211-237. https://doi.org/10.1075/jslp.1.2.04jul.

Kalikow, D. N., Stevens, K. N., \& Elliott, L. L. (1977). Development of a test of speech intelligibility in noise using sentence materials with controlled word predictability. The Journal of the Acoustical Society of America, 61(5), 1337-1351. https://doi. org/10.1121/1.381436.

Kang, O., Thomson, R., \& Moran, M. (2019). The Effects of international accents and shared first language on listening comprehension tests. TESOL Quarterly, 53(1), 56-81.

Lather, P. (2017). Validity, qualitative. In (Post) Critical Methodologies: The Science Possible After the Critiques (pp. 75-80). London: Routledge.

Leong, L. M., \& Ahmadi, S. M. (2017). An analysis of factors influencing learners' English speaking skill. International Journal of Research in English Education, 2(1), 34-41.

Likert, R. (1932). A technique for the measurement of attitudes. Archives of Psychology, 140, 5-55.

Munro, M. J., \& Derwing, T. M. (2015). Intelligibility in research and practice: Teaching priorities. in $\mathrm{M}$. Reed \& J. M. Levis (Eds.), The Handbook of English Pronunciation (pp. 377-396). Hoboken, NJ: Wiley.

Natalia, C., Andrew, A., \& George, F. J. (2017). Hepatic encephalopathy and foreign accent syndrome: A case report. International Journal of Hepatology and Gastroenterology, 3(1), 38-40.

Palacios, V. A. (2009). Pronunciation instruction: Improving the intelligibility and comprehensibility of EFL learners in Mexico and the relationship between comprehensibility and foreign accent. San Andrés Cholula: Universidad de las Américas Puebla.

Palinkas, L. A., Horwitz, S. M., Green, C. A., Wisdom, J. P., Duan, N., \& Hoagwood, K. (2015). Purposeful sampling for qualitative data collection and analysis in mixed method implementation research. Administration and Policy in Mental Health and Mental Health Services Research, 42(5), 533-544.

Ryalls, J., \& Perkins, R. (2017). Foreign accent syndrome: Phonology or phonetics? In A. Lahiri \& S. Kotzor (Eds.), The Speech Processing Lexicon:
Neurocognitive and Behavioural Approaches (pp. 187-192). Berlin, Boston: De Gruyter.

Saito, K., \& Shintani, N. (2016). Foreign accentedness revisited: Canadian and Singaporean raters' perception of Japanese-accented English. Language Awareness, 25(4), 305-317.

Schroeder, R. W., Baade, L. E., Coady, E. L., Massey, A. D., \& Wolford, L. M. (2016). Neurological and neuropsychological assessment of a patient with foreign accent syndrome following oral and maxillofacial surgery. Psychology \& Neuroscience, 9(3), 379-389.

Setter, J., Sewell, A., \& Ryder, C. (2014). The Hong KongEnglish accent: Judgements by listeners in Britain. In Proceedings of the International Symposium on the Acquisition of Second Language Speech: Concordia Working Papers in Applied Linguistics (Vol. 5, pp. 650-666). Quebec: Concordia University.

Stocker, L. (2017). The impact of foreign accent on credibility: An analysis of cognitive statement ratings in a Swiss context. Journal of Psycholinguistic Research, 46(3), 617-628.

Sugimoto, J., \& Uchida, Y. (2018). Accentedness and acceptability ratings of Japanese English teachers' pronunciation. In J. Levis (Ed.), Proceedings of the $9^{\text {th }}$ Pronunciation in Second Language Learning and Teaching Conference (pp. 30-40). Ames, IA: Iowa State University.

Suyanto, T., Setyowati, R., \& Pramono, M. (2017). Building students' multicultural values through citizenship education to create a democratic society. Advanced Science Letters, 23(12), 11702-11705.

Thomas, D. R. (2017). Feedback from research participants: Are member checks useful in qualitative research? Qualitative Research in Psychology, 14(1), 23-41.

Van Kuyk, S., Kleijn, W. B., \& Hendriks, R. C. (2018). An instrumental intelligibility metric based on information theory. IEEE Signal Processing Letters, 25(1), 115-119.

Yazan, B. (2015). Intelligibility. ELT Journal, 69(2), 202204. 